$$
\begin{array}{cccc}
\text { S sciendo } & \text { International Conference KNOWLEDGE-BASED ORGANIZATION } \\
\text { Vol. XXVII } & \text { No } 2 & 2021
\end{array}
$$

\title{
POSSIBILITIES OF THE CONTRACTING AUTHORITY TO AMEND THE PUBLIC PROCUREMENT CONTRACT/FRAMEWORK AGREEMENT
}

\author{
Ioan Gabriel POPA \\ “Nicolae Bălcescu” Land Forces Academy, Sibiu, Romania \\ popaigabi@yahoo.com
}

\begin{abstract}
The experience gained in the field of public procurement leads me to the statement that the activity of amending the public procurement contract / framework agreement is a challenging activity for the contracting authority. Maybe not from the perspective of elaborating the documents necessary to operate the change or changes that may be required during the development of the public procurement contract / framework agreement, but rather from the perspective of the solutions offered by the law, solutions that cover only certain areas. Starting from the normative acts in force, this paper aims to identify the situations and the way in which the contracting authority can modify the public procurement contract / framework agreement, the documents to be elaborated and the effects that the modifications might entail. In order to increase transparency, predictability and coherence in relation to the operation of contractual changes, contracting authorities should carry out analyses after each public procurement process as well as of the various practical situations encountered during the execution of contracts.
\end{abstract}

Keywords: public procurement contract, framework agreement, public procurement acquisition, clause review, price review

\section{Introduction}

The package of normative acts issued since 2016, the year in which the "National Strategy in the Field of Public Procurement" was written for the first time in the modern history of Romania, contains information on the possibility of the contracting authority to amend the public procurement contract / framework agreement. From this perspective, it is necessary to know the possibilities of the contracting authority from the perspective of the time when the modification can be made, of the modality of the modification and of the effects these modifications entail. The experience gained in the field of public procurement makes me argue that the activity of amending the public procurement contract/framework agreement is a challenging activity for the contracting authority both from the perspective of elaborating the documents necessary to operate the change or changes brought to the public procurement contract / framework agreement, as well as from the perspective of the solutions offered by the law, solutions that are limited to specific areas.

Starting from the normative acts in force, this paper aims to identify the situations and the way in which the contracting authority can modify the public procurement contract / framework agreement, the documents to be elaborated and the effects that the modifications might entail. 
2. Normative acts governing the activity of amending the public procurement contract / framework agreement

The aspects that are taken into account when the contracting authority intends to modify the public procurement contract / framework agreement are contained in the following normative acts:

- Chapter V - "Execution of the public procurement contract / framework agreement", Section 2 "Modification of the public procurement contract / framework agreement" of the Law on Public Procurement no. 98/2016, with subsequent amendments and completions;

- Chapter VI "Execution of the sectoral contract", Section 2 "Modification of the sectoral contract / framework agreement" of the Law on Sectoral Procurement no. 99/2016, with subsequent amendments and completions;

- Chapter V "Rules regarding the execution of concession contracts", Section 2 "Modification of the concession contract" of the Law on Work and Service Concessions no. 100/2016, with subsequent amendments and completions;

- Chapter IV "Execution of the public procurement contract / framework agreement", Section 2, Section 4 "Modification of the public procurement contract / framework agreement" of G.D. no. 395, of June 2, 2016, for the approval of the Methodological Norms for the Application of the Provisions Regarding the Award of The Public Procurement Contract / Framework Agreement of Law no. 98/2016 on Public Procurement;

- Chapter IV "Execution of the sectoral contract / framework agreement", Section 2 "Modification and completion of the sectoral contract / framework agreement" of G.D. no. 394. of June 2, 2016. for the approval of the Methodological Norms for the
Application of the Provisions Regarding the Award of The Public Procurement Contract / Framework Agreement of Law no. 99/2016 on Sectoral Procurement;

- Order of the President of NAPP (National Authority for Public Procurement) regarding the approval of the Selection Methodology and Interaction of The Contracting Authorities / Entities with the National Agency for Public Procurement no. $141 / 2017$

- NAPP Instruction no. 1/2021 on amending the public procurement contract / sectoral procurement contract / framework agreement

3. Concrete ways of interpreting the contracting authority's provisions on the possibility to modify the public procurement contract / framework agreement

The provisions of Art. 221 Par. (1) Letter a) of the Law on Public Procurement no. $98 / 2016$, as well as in the provisions of Art. 236 Par. (1) of the Law on Sectoral Acquisitions no. 99/2016 and also in the provisions of Art. 100 of the Law on Work and Service Concessions no. 100/2016, all mention the same aspect, obviously taking into account the scope of the procurement, namely "Public procurement contracts / Framework agreements may be amended, without organizing a new award procedure, ..... a) when the changes, regardless of their value, have been provided in the initial procurement documents in the form of clear, precise and unequivocal review clauses, which may include price review clauses" [1].

In other words, the legislator creates the premises for amending the contract / framework agreement if this was originally provided for in the award documentation with the help of review clauses that must be clear, precise and unequivocal.

Moreover, the provisions of Art. 221 Par. (2) of the Law on Public Procurement no. 
98/2016, as well as the provisions of Art. 236 Par. (2) of the Law on Sectoral Acquisitions no. 99/2016 and Art. 100 of the Law on Work and Service Concessions no. 100/2016, stipulate that "the review clauses specify the limits and nature of possible changes, as well as the conditions under which they may be used and cannot not establish changes or options that would affect the general nature of the public procurement contract or framework agreement" [2].

Starting from the two legislative clarifications, the questions that a contracting authority can ask itself are legitimate: When can the change be made?, How can the change be made? or Why make the change?

The answer to the first question could be: when the contracting authority finds a discrepancy between the provisions of the award documentation and the concrete situation in which the signatory parties of the contract / framework agreement find themselves. The contracting authority will certainly think 10 times before making the change, taking into account aspects such as: whether this change will comply with the legal framework, whether or not it is substantial, what will control evaluate (internal audit, external audit, National Agency for Public Procurement, hereinafter referred to as NAPP, etc.). In such situations, the specialized departments, those that have made the report of necessity and the specifications, together with the lawyer, chief accountant or economic director will identify solutions, starting from the verification of existing review clauses in the content of the contract / framework agreement.

The answer to the second question could be: as provided for in the review clauses mentioned in the award documentation. If these clauses are not identified, the contracting authorities will consider whether they can invoke the provisions of Art. 221 Par. (1) Letter e) or f) of the Law on Public Procurement no. 98/2016 or the provisions of Art. 241 of the Law on Sectoral Procurement no. 99/2016, which state: "e) when the changes, regardless of their value, are not substantial; f) without the need to verify whether the conditions provided in Par. (7) Letter. a)-d)... .. ", or even the application of a procedure such as negotiation without prior publication, given that this procedure is exempted from the notification of NAPP [3].

The answer to the last question may be: if the change is not operated, then the procurement will not fully meet the requirements of the contracting authority.

Another thing that we can identify by analyzing the previous legislative provisions, is the fact that the modification of the contract / framework agreement can be done without organizing a new public procurement procedure. However, in order to take the decision not to organize a new procedure, the contracting authority must find out the cost of the new change proposed to be made in order to accept it. In this situation, when the need for a change arises, this change must be made in strict accordance with the contractual provisions, because the revision guidelines can only refer to the object of the contract and therefore to its content. If we deal with quantity supplementation, it can be done only if this was provided for in the contract / framework agreement.

Even if the provisions of Art. 221 Par. (1) Letter a) of the Law on Public Procurement no. 98/2016 and the provisions of Art. 236 Par. (1) of the Law on Sectoral Acquisitions no. 99/2016, refer to the fact that the modifications of the contract / framework agreement do not have a value limit, this limitation is imposed by the existence of a clause that allows this in the award documentation.

From a legislative perspective, review clauses must be clear, precise and unequivocal. If we analyze the behavior of a contracting authority from the perspective of imposing some revision clauses in the contract, we notice that most of the times 
they copy existing contract models on the market and do not focus so much on the complexity of the procurement. Consequently, these review clauses are sometimes not suitable for the acquisition.

In what regards the legislative specification related to the price review guidelines, we mention that the provisions of Art. 164 of G.D. 395 / 2016, and the provisions of Art. 158 of G.D. 394/2016 indicate priceadjusting method: "the price can be updated if certain conditions have appeared on the market, as a result of which the increase / decrease of price indices for constituent elements of the offer have been identified, and their effect is reflected in the increase / decrease of the costs on the basis of which the contract price was based". This method is also detailed by NAPP Instruction no.1 / 2021 [4]. In other words, the price can be adjusted in the sense of increasing or decreasing it as a result of the appearance of some conditions that may emerge on the market only if such a clause exists in the initial contract / framework agreement. In principle, and especially for products whose prices fluctuate a lot on the market (e.g.: building materials), it is recommended that the contracting authority impose in the contract a formula for price update according to the evolution of a statistical indicator (e.g.: price index for consumption).

Another aspect taken into account by the legislators when a modification the contract / framework agreement is intended is stipulated in the provisions of Art. 221 Par. (1) Letter b), letter c) and Par. (3) of Law 98/2016 and in the provisions of Art. 237 and 238 of the Law 99/2016, namely the realization of the procurement "for additional works, services or products from the initial contractor, up to a maximum of $50 \%$ of the value of the initial contract, which became necessary and were not included in the initial procurement procedure". We observe that, on the one hand, there is a value limitation of up to $50 \%$ of the value of the initial contract (there is no limit for the sectorial ones) and, on the other hand, the specification that the acquisition will be made by the initial contractor (the contractor cannot change, because the change "is impossible for economic or technical reasons, such as requirements for interchangeability or interoperability with existing equipment, services or facilities purchased under the initial procurement procedure" and "would generate a significant increase in costs the contracting authority" [5]). This situation can usually help the contracting authority when it wishes to resolve a deficiency in the award documentation and that had been discovered after the awarding.

Another case of change would appear when "the change became necessary as a result of circumstances which a diligent contracting authority could not have foreseen" [6]. In this case, in order for the change to take place, the other two conditions must be met cumulatively: "the change does not affect the general nature of the contract" and "the price increase does not exceed $50 \%$ of the value of the public procurement contract / initial framework agreement". Obviously, in such situations the contracting authority is, on the one hand, in a difficult situation in justifying unforeseeable circumstances, situations which it could not have foreseen initially, and, on the other hand, in respecting the general character of the contract, i.e. the general objectives pursued by the contracting authority, the main object of the contract, the main rights and obligations, etc.

Another possibility to modify the contract / framework agreement, without using a procurement procedure, can be done according to the provisions of Art. 221 Par. (1) Letter d) of Law 98/2016 and to the provisions of Art. 240 of Law 99/2016, when "the contractor with whom the contracting authority initially concluded the public procurement contract is replaced by a new contractor", but only in the following situations: 
- "as a result of a review clause or an option established by the contracting authority;

- the rights and obligations of the initial contractor resulting from the public procurement contract are taken over, as a result of a universal succession in a reorganization process, including by merger, division, acquisition or insolvency, by another economic operator that fulfills the initiallyestablished qualification and selection criteria, provided that this change does not involve other substantial changes to the public procurement contract and is not carried out in order to circumvent the application of the award procedures provided by this law;

- if the contracting authority assumes the obligations of the main contractor towards its subcontractors, respectively towards the contracting authority".

In addition, the contracting authority may change the initial contractor if "upon early termination of the contract, the contractor assigns, at request, the contracts concluded with its subcontractors to the contracting authority / entity" [7].

Contracting authorities may make changes "where the changes, regardless of their value, are not substantial" [8]. Thus, in order to determine that a possible change is not substantial, the contracting authority must exclude those which are substantial, as follows:

"a) the amendment introduces conditions which, if included in the initial award procedure, would have allowed the selection of candidates, other than those initially selected or the acceptance of an offer other than the one initially accepted, or would have attracted other participants in the award procedure;

b) the amendment changes the economic balance of the public procurement contract I framework agreement in favor of the contractor in a manner not provided for in the initial public procurement contract / framework agreement;

c) the amendment considerably extends the object of the public procurement contract I framework agreement;

d) a new contractor replaces the original contractor, in other cases" [9].

Another substantial modification is considered the adjustment by revision / updating of the contract price as provided by NAPP Instruction no.1./2021.

A last possibility to amend the contract / framework agreement for which the contracting authority is not obliged to organize a procurement procedure, van occur when there are no substantial changes and "without the need to verify that the conditions are met" [10] as provided by the thresholds stipulated in Art. 7 of Law $98 / 2016$, if the following conditions are cumulatively met:

- the value of the change is lower than the value thresholds for which it is advertised in the Official Journal of the European Union;

- the value of the change is less than $10 \%$ of the price of the initial public procurement contract, in case of public procurement of services or products, or less than $15 \%$ of the price of the initial public procurement contract, in case of public procurement work contracts;

- the amendment is without prejudice to the general nature of the contract or framework agreement on the basis of which the subsequent contract is awarded.

\section{Conclusions}

All the mentioned possibilities of modification of the public procurement contract / framework agreement are provided during their development period and presuppose the modification without the organization of a new procurement procedure, as stipulated in the provisions of Art. 221 of the Law on Public Procurement no. $98 / 2016$, as well as in the provisions of 
Art. 236 of the Law on Sectoral Procurement no. 99/2016.

Provided that the amendment of the public procurement contract / framework agreement cannot be applied without organizing a new procurement procedure, the contracting authority has the possibility to organize a new award procedure during the validity period of the contract and to unilaterally terminate the initial contract. Unfortunately, the normative acts in force do not specify the manner in which the unilateral modification or denunciation of the initial contract is made, nor the documents in which these actions are materialized. Hence the acute need for complete regulation of the contracting authority's activity for carrying out specific activities in the field of public procurement. In order to increase transparency, predictability, and unity in relation to the operation of contractual changes, contracting authorities must carry out analyses after each public procurement process, as well as after having experienced delicate situations encountered in the execution of contracts.

\section{References List}

[1] Art. 221 Par. (1) Letter a) of the Law on Public Procurement no. 98/2016, as well as in the provisions of Art. 236 Par. (1) of the Law on Sectoral Procurement no. 99/2016 and also in the provisions of Art. 100 of the Law on Work and Service Concessions no. $100 / 2016$.

[2] Art. 221 Par. (2) of the Law on Public Procurement no. 98/2016, as well as the provisions of Art. 236 Par. (2) of the Law on Sectoral Procurement no. 99/2016.

[3] Art.6 Par. (3) din GEO 98/2017 on the ex ante control function of the process of awarding public procurement contracts / framework agreements, sectoral contracts / framework agreements and work and service concession contracts.

[4] NAAP no.1/2021- regarding the amending the public procurement contract / sectoral procurement contract / framework agreement.

[5] Art. 221 Par. (1) Letter b), and Par. (3) of the Law on Public Procurement 98/2016.

[6] Art. 221 Par. (1) Letter c), and Par. (3) of the Law on Public Procurement 98/2016.

[7] NAAP no.1/2021- regarding the amending the public procurement contract / sectoral procurement contract / framework agreement.

[8] Art. 221 Par. (1) Letter e) of the Law on Public Procurement 98/2016 and Art.240 Par. (2) of the Law on Sectoral Procurement no. 99/2016.

[9] Art.221 Par. (7) of the Law on Public Procurement 98/2016. 